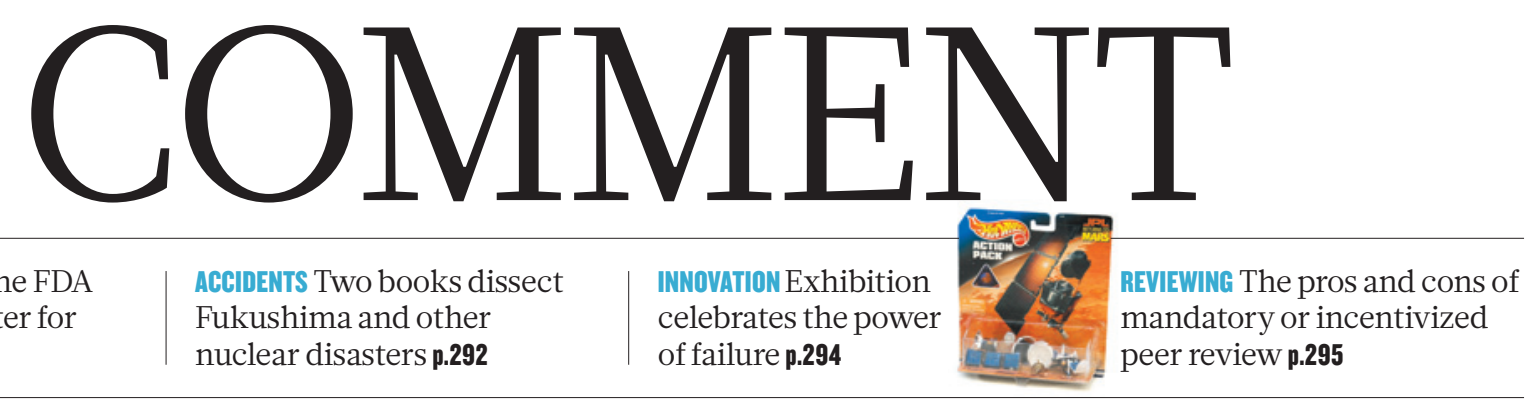

PoLICY How should the FDA regulate faecal matter for transplants? p.290 nuclear disasters p.292
REVIEWING The pros and cons of peer review $\mathbf{p . 2 9 5}$

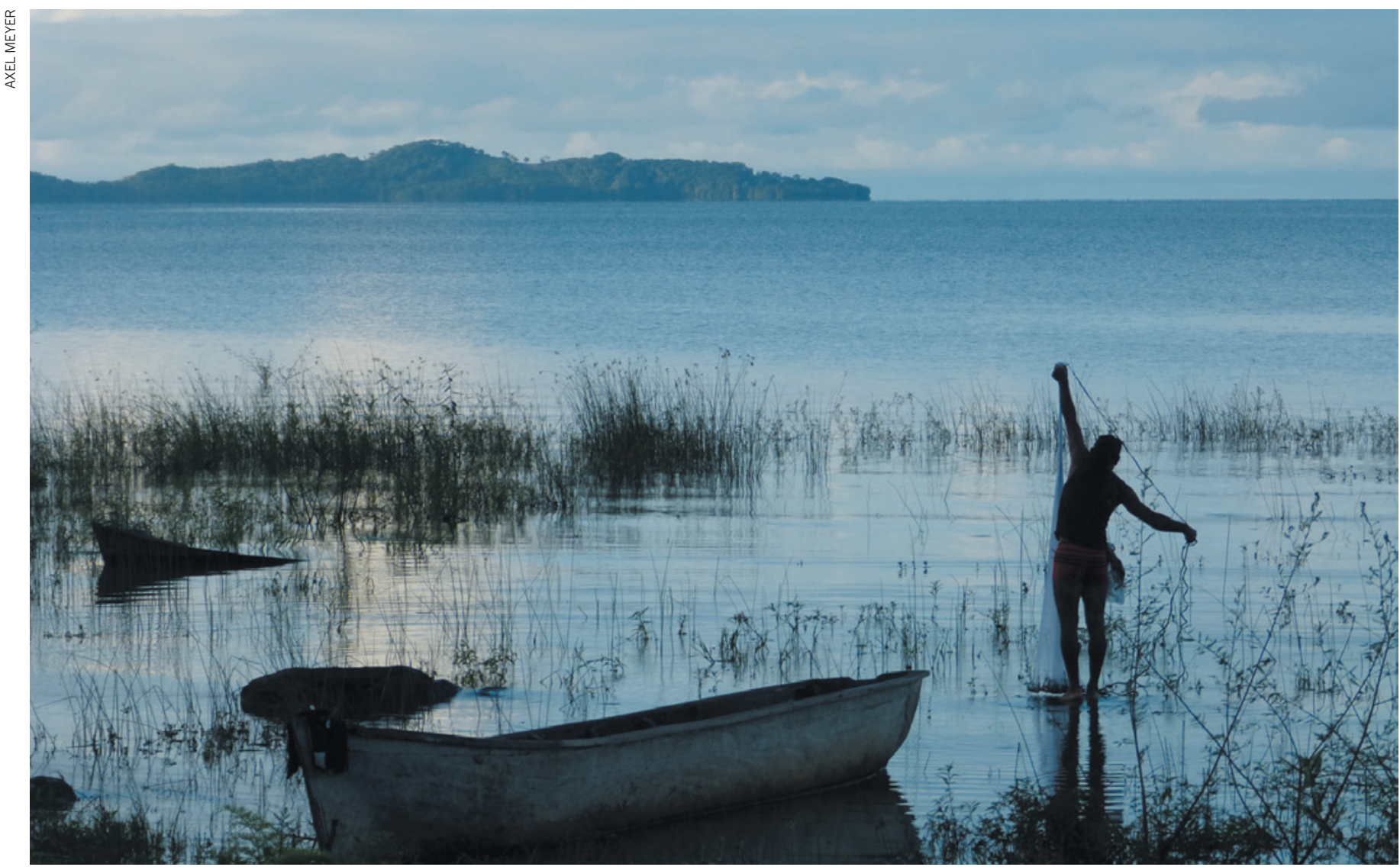

Lake Nicaragua is the largest drinking-water reservoir in Central America and is home to fish species key to evolutionary science.

\title{
Nicaragua Canal could wreak environmental ruin
}

Plans for a 300-kilometre waterway joining the Pacific and Atlantic oceans need independent environmental assessment, urge Axel Meyer and Jorge A. Huete-Pérez.

$\mathrm{L}$ ast June, the Nicaraguan government granted a concession to a Hong Kong company to build a canal connecting the Pacific Ocean and the Atlantic Ocean, through the Caribbean Sea. The HK Nicaragua Canal Development Investment Company (operating as HKND Group) signed a 50 -year lease, renewable for another 50 years.
It plans to break ground in December after spending this year establishing a route and conducting feasibility studies. Included in the concession are the rights to build and operate industrial centres, airports, a rail system and oil pipelines, as well as land expropriation and the rights to natural resources found along the canal route.
The Nicaraguan government says that the US\$40-billion project will boost economic growth in the country - the secondpoorest nation in the Americas - from 4.5\% in 2013 to $14.6 \%$ in 2016 . No economic or environmental feasibility studies have yet been revealed to the public. Nicaragua has not solicited its own environmental $>$ 
$\checkmark$ impact assessment and will rely instead on a study commissioned by the HKND. The company has no obligation to reveal the results to the Nicaraguan public.

In our view, this canal could create an environmental disaster in Nicaragua and beyond. The excavation of hundreds of kilometres from coast to coast, traversing Lake Nicaragua, the largest drinking-water reservoir in the region, will destroy around 400,000 hectares of rainforests and wetlands.

The accompanying development could imperil surrounding ecosystems. Some 240 kilometres north of the most likely route of the canal lies the Bosawas Biosphere Reserve -2 million hectares of tropical forest that is the last refuge of many disappearing species (see 'Nicaragua carve-up'). Less than 115 kilometres to the south is the Indio Maiz Biological Reserve, with more than 318,000 hectares of tropical dry forest. Worse still, the probable canal route cuts through the northern sector of the Cerro Silva Natural Reserve.

The project threatens multiple autonomous indigenous communities such as the Rama, Garifuna, Mayangna, Miskitu and Ulwa, and some of the most fragile, pristine and scientifically important marine, terrestrial and lacustrine ecosystems in Central America.

An international community of conservationists, scientists and sociologists needs to join the concerned citizens and researchers of Nicaragua in demanding two things: first, independent assessments of the repercussions of this mega-project; and second, that the Nicaraguan government halt the project should the assessments confirm fears that this canal will yield more losses than gains for the region's natural resources, indigenous communities and biodiversity.

\section{AT WHAT PRICE?}

Many have dreamed of a canal through Nicaragua - from the Spanish conquistadors to Napoleon III. The US industrialist Cornelius Vanderbilt, the United States and the United Kingdom all had plans for such a canal by the mid1800s, well before the Panama Canal was completed in 1914. Engineering challenges, projected costs

"Inhabitants of all species with ancient ties to the land will be uprooted."

and, more recently, competition with the Panama Canal, have prevented such plans from being realized.

The most likely route ${ }^{1}$ of the HKND's canal is 286 kilometres long and would cut an approximately 90-kilometre swathe across Lake Nicaragua, requiring a major transformation of the lake bed and local rivers. To rival the expanded Panama Canal (slated for completion in 2015) by accommodating

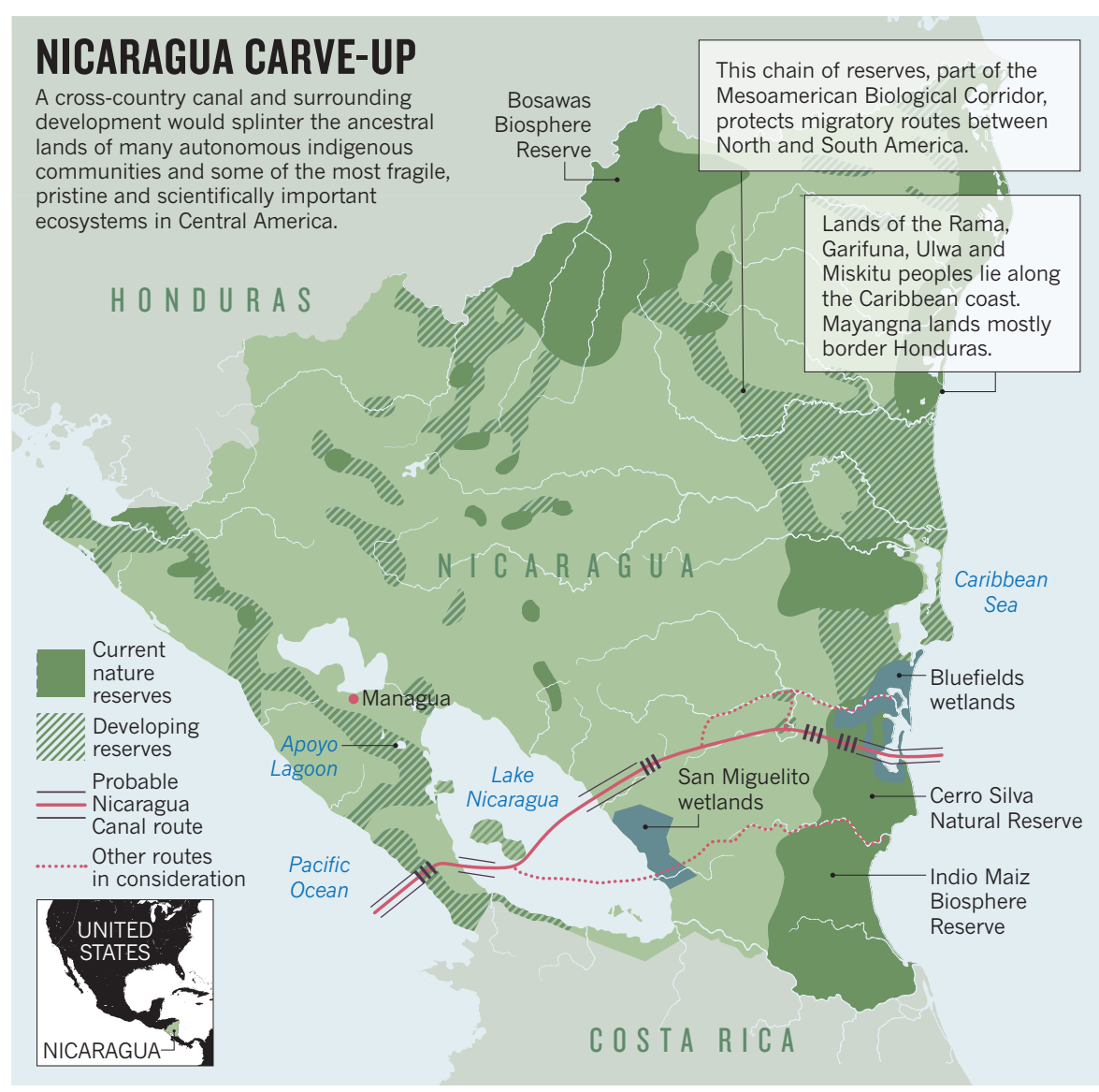

ships of up to 400,000 tonnes, the proposed Nicaraguan waterway will be 27.6 metres deep, and the HKND has claimed that it may be an implausible 520 metres wide. Lake Nicaragua, however, has an average depth of only 15 metres. The extensive dredging required would dump millions of tonnes of sludge either into other parts of the lake or on to nearby land. Either way, the sludge will probably end up as damaging sedimentation ${ }^{2}$.

Lake Nicaragua would also serve as the reservoir for the canal's lock system, requiring dams to be constructed in an area of frequent seismic activity, which would increase the risk of local water shortages and flooding. The lake would probably suffer from salt infiltration in the lock zones, as in locks of the Panama Canal. This would transform a freeflowing freshwater ecosystem into an artificial slack-water reservoir combined with salt water. Declining populations of native aquatic fauna such as euryhaline bull sharks, sawfish and tarpon, important for sport fishing and tourism, could also suffer.

Changes in chemical composition and disruptions to dissolved oxygen levels in the water from pollutants and construction could harm numerous populations of freshwater and marine fish found nowhere else in the world ${ }^{3}$. Boat wakes and dredging could weaken and denude the shoreline of rivers leading inland from the new ports on both coasts ${ }^{4}$. This could affect the rivers Escondido,
Rama and Oyate on the Atlantic side, and Las Lajas and Brito on the Pacific side.

Invasive species from container bilge water are another concern. The arrival of nonnative fish can have catastrophic results, as demonstrated by the dramatic decline in Lake Nicaragua's cichlid fish population since the introduction of African tilapia in the $1980 s^{5}$. Cichlids are central to evolutionary research. Ecology and genetics studies over four decades have resulted in tens of publications involving researchers from more than a dozen countries. One study, for example, revealed that in less than 10,000 years, several species of cichlid evolved from one population in the Apoyo Lagoon, a crater lake close to Lake Nicaragua ${ }^{6}$.

Other vulnerable ecosystems ${ }^{7}$ in the Cerro Silva-Indio Maiz-La Selva Corridor, such as the biodiversity-rich wetlands of San Miguelito and Bluefields, will suffer from dredging, sedimentation, invasive species, emissions and other pollution. Shipping and the construction and operation of deepwater ports ${ }^{8}$ on the Atlantic and Pacific coasts will affect the nesting and egg-laying habitats of several endangered sea turtles and threaten coral reefs and mangroves.

On land, animal populations will be artificially confined to territories carved out by the canal's infrastructure and accompanying projects, disrupting migration patterns, connectivity and ecological dynamics. Already, 

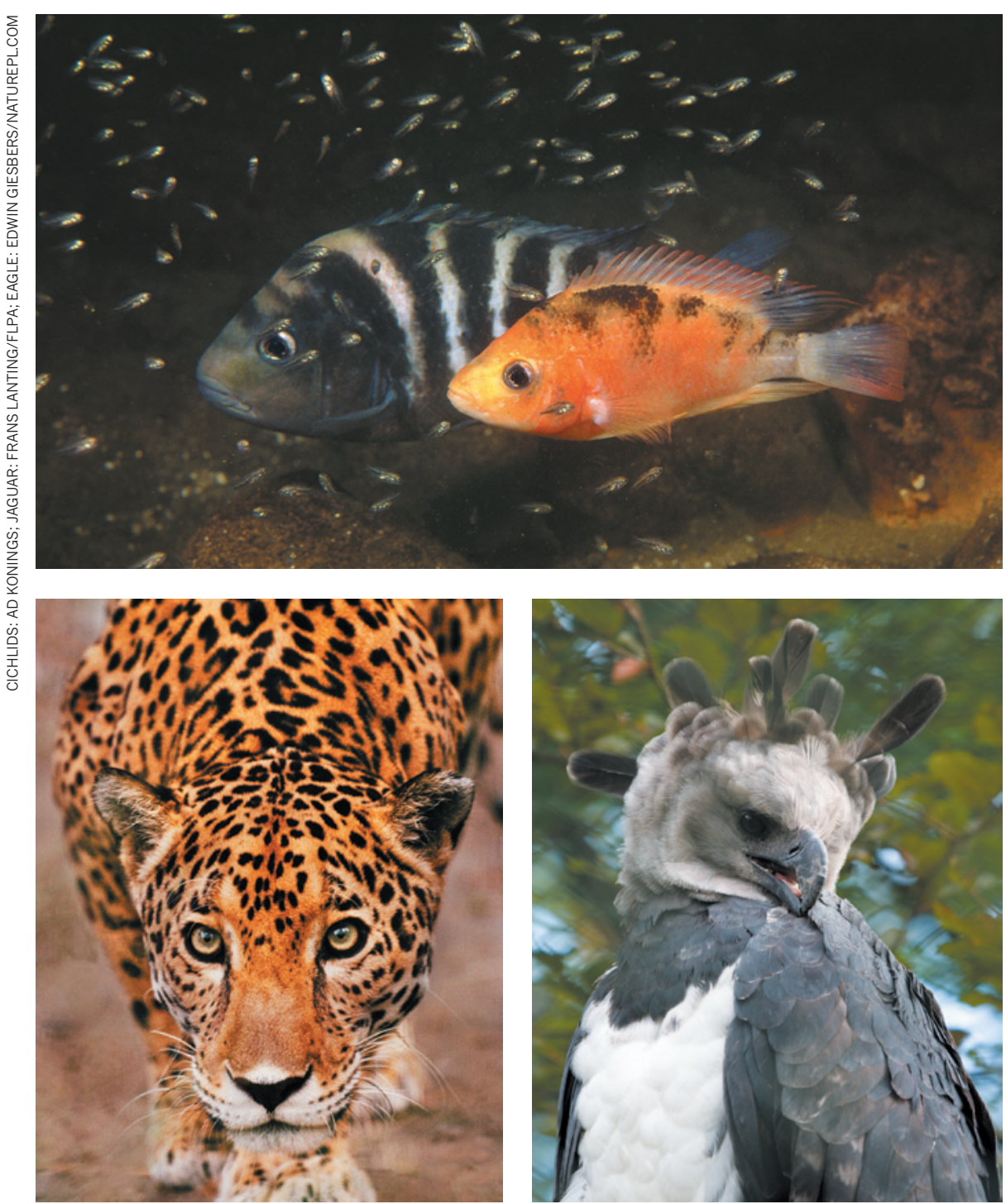

Cichlid fish, jaguars and harpy eagles are among the many species threatened by the Nicaragua Canal.

the extraordinary concentrations of endemic species in the Mesoamerican Biological Corridor are experiencing rapid habitat loss. This crucial biodiversity hotspot is a conservation system established in 1997 by Mexico and the countries of Central America to limit human activity and to create a safe migratory corridor between North and South America.

Nicaragua's Indio Maiz and Bosawas biosphere reserves - key links in this corridor - sandwich possible canal routes. Hundreds of thousands of hectares of the forests and wetlands would be cleared for the canal, destroying the habitats and food sources of already endangered species such as the Baird's tapir (Tapirus bairdii) ${ }^{9}$, the spider monkey (Ateles geoffroyi), the harpy eagle (Harpia harpyja) and the jaguar (Panthera onca), a creature of mystical importance to Mesoamerican cultures.

The social, economic, cultural and environmental costs of population resettlement are expected to be enormous. Hundreds of villages will have to be evacuated and the indigenous inhabitants relocated. Archaeological sites along the route of the canal will be in danger too. This upheaval could reignite the civil violence that has long blighted the region. The situation is already tense as outsiders invade ancestral lands with cattle and carry out illegal logging.

Might there be an economically, geographically and politically feasible route for the proposed canal, railway and oil pipeline that would entail significantly reduced risk? The general consensus in Nicaragua is no. Inhabitants - of all species - with ancient ties to the land will be uprooted regardless.

\section{INTERNATIONAL ACTION}

The contract for an interoceanic canal in Nicaragua represents a classic example of the challenges faced by a developing country in balancing economic growth and environto raise revenue and employment from Lake Nicaragua could include expanded irrigation, tourism and aquaculture. The mental protection. More sustainable ways population of Nicaragua is expected to grow by $37 \%$ by 2050 , so water shortages and pressure on natural resources are already set to increase, limiting sustainable growth and public welfare. In preparation for a future of climate change, food insecurity and biodiversity loss, Nicaragua must establish long-term measures for the protection of its environment, not sacrifice itself to speculators.

A loose coalition of more than 30 concerned groups filed legal complaints with the government of Nicaragua in the second half of last year. These included three communities - the Miskitu and Ulwa indigenous peoples and the Rama-Kriol territorial government in the South Atlantic Autonomous Region - arguing that the canal concession violates their land rights and legal autonomy (see go.nature.com/ttshoc). These legal petitions were overridden by the National Assembly in December.

Swift and decisive international action is called for. The Nicaraguan Academy of Sciences (of which one of us, J.A.H.-P., is president) is coordinating efforts with the InterAmerican Network of Academies of Sciences to carry out an independent impact assessment. We need more conservation groups and social organizations to lend their expertise and funds if we are to prevent the tragic devastation of indigenous communities along with terrestrial, marine and freshwater biodiversity and resources in Central America.

Jorge A. Huete-Pérez is director of the Centre for Molecular Biology at the Universidad Centroamericana, Managua, Nicaragua, and the president of the Nicaraguan Academy of Sciences. Axel Meyer is professor of zoology and evolutionary biology at the University of Konstanz, Germany.

e-mails: jorgehuete@uca-cbm.org; axel.meyer@uni-konstanz.de

1. Comisión de Trabajo del Gran Canal Interoceanic Canal Through Nicaragua: Project Profile (2006); available at http://go.nature.com/psvowd (Spanish).

2. Klytchnikova, I. I., Cestti, R. E., Escurra, J., Jorge J. \& Pagiola, S. P. Policy and Investment Priorities to Reduce Environmental Degradation of the Lake Nicaragua Watershed (Cocibolca) (World Bank, 2013); available at http://go.nature.com/91 ruql.

3. Elmer, K. R., Kusche, H., Lehtonen, T. K. \& Meyer, A Phil. Trans. R. Soc. B 365, 1763-1782 (2010).

4. Wilber, C. G. Turbidity in the Aquatic Environment: An Environmental Factor in Fresh and Oceanic Waters (Charles Thomas, 1983).

5. McKaye, K. R. et al. BioScience 45, 406-411 (1995).

6. Barluenga, M., Stölting, K. N., Salzburger, W. Muschick, M. \& Meyer, A. Nature 439, 719-723 (2006).

7. Verones, F., Pfister, S. \& Hellweg, S. Environ. Sci. Technol. 47, 9799-9807 (2013).

8. Corbett, J. J. et al. Environ. Sci. Technol. 41, 8512-8518 (2007)

9. Jordan, C. A., Stevens, K. J., Urquhart, G. R., Kramer, D. B. \& Roe, K. Tapir Conserv. 19, 11-15 (2010). 